\title{
Influência do uso de tecnologias de informação e comunicação na prestação de contas públicas municipais - um estudo de caso no Tribunal de Contas dos Municípios do estado da Bahia
}

\author{
Audálio Fernandes dos Reis \\ Universidade Federal de Sergipe \\ Antonio Luiz Rocha Dacorso \\ Universidade Federal de Sergipe \\ Fernando Antonio Guimarães Tenório \\ Universidade Federal de Sergipe
}

\begin{abstract}
A representatividade dos municípios brasileiros como entes jurídico, econômico e social, na administração pública é relevante tanto para a alocação quanto para a aplicação de recursos. A prestação de contas é obrigatória para quem utiliza, arrecada, guarda ou administra dinheiro, bens e valores públicos. Esta pesquisa buscou, por meio de um estudo de caso único, identificar a influência das tecnologias de informação e comunicação na prestação de contas. Como resultado, foram encontradas as seguintes contribuições: envio das informações diretamente das prefeituras ao Tribunal de Contas através da internet; redução de erros e eliminação das redundâncias; processo mais célere; e, além das anteriores, permissão de cruzamento e comparação de dados.
\end{abstract}

Palavras-chave: prestação de contas públicas; tecnologia da informação; Tribunal de Contas.

Influencia de la utilización de la información y la comunicación en responsabilidad del gobierno municipal - un estudio de caso en el Tribunal de Contas dos Municípios do estado da Bahia La representatividad de los municipios brasileños como ente, económico y social, en la administración pública es relevante cuanto a la aportación y aplicación de recursos. La prestación de cuentas es obligatoria para quien utiliza, recauda, guarda o administra dinero, bienes y valores públicos. Esta pesquisa buscó, por medio de un estudio de caso único, identificar la influencia de las tecnologías de la información y comunicación en la prestación de cuentas. Como resultado, fueran encontradas las siguientes contribuciones: envío de las informaciones directamente de los municipios ante el Tribunal

DOI: http://dx.doi.org/10.1590/0034-76121664

(cc) BY-NC

Artigo recebido em 29 jul. 2013 e aceito em 22 ago. 2014. 
de Cuentas a través de internet; reducción de erros y eliminación de las redundancias; proceso más veloz; y, además de lo anterior, permisión de cruzamientos y comparación de datos.

Palabras clave: responsabilidad pública; tecnología de la información; tribunal de cuentas.

Influence of the use of information and communication technologies in municipal government accountability - a case study in the Court of Auditors of Bahia's municipalities

Representativeness for Brazilian municipalities as being judicial, economic and social entity in the public administration is relevant regarding both the allocation and the use of resources. Accountability is a must for anyone who uses, collects, saves and manages money, goods and public values. This study attempted, through a single case study, to identify the influence of information and communication technologies in accountability. As a result, we found the following contributions: sending information directly from the town-halls (municipalities) to the Court of Auditors through the internet; reducing errors and eliminating redundancies; accelerating the process; and permission of crossing and comparing data.

KEYWORDs: accountability of public accounts; information technology; court of auditors.

\section{Introdução}

A prestação de contas nos Estados democráticos de direito é dever de todo aquele que assume o poder público (Pereira, 2010). O gestor governamental tem a responsabilidade de prestar contas de suas ações, o que significa apresentar o que faz, como faz e por que faz, e responder por seus atos ou omissões perante o contexto social no qual está inserido (Abrucio e Loureiro, 2004; Diamond e Morlino, 2005).

Constitucionalmente, a função de acompanhar a prestação de contas públicas é atribuída ao Poder Legislativo auxiliado pelo Tribunal de Contas, dentro da esfera do governo federal, estadual ou municipal, a que pertençam essas contas (Brasil, 1988).

O surgimento do primeiro tribunal de contas no Brasil data mais de um século e entre idas e vindas houve uma significativa expansão em sua missão, que passou, com a Constituição de 1988, a não exercer apenas o controle contábil, financeiro e orçamentário exclusivamente sob a ótica da legalidade, mas também adquiriu a competência para fiscalizar aspectos operacionais e patrimoniais quanto à legitimidade e à economicidade das despesas realizadas (Costa, 2005).

Em função da grande quantidade de documentos que deve ser analisada pelos Tribunais de Contas e, ainda, das dificuldades inerentes à manipulação, ordenação e armazenamento de documentos, o processo de acompanhamento de prestação de contas tornou-se lento. Para otimizá-lo, os Tribunais de Contas fizeram, de maneira crescente, o uso de Tecnologias de Informação e Comunicação (TICs), para informatizar gradativamente as fases do acompanhamento da prestação de contas. Essa informatização substituiu os procedimentos tradicionais de manipulação e ordenamento de documentos, preenchimento de formulários e confecção manual de relatórios por captação dos dados on-line e geração informatizada de relatórios 
(Zamot, 2003). A substituição desses procedimentos tradicionais provocou mudanças nos processos então em uso, nas formas de apresentação e na sua gestão, o que conduziu à seguinte questão de pesquisa: Como a adoção de TICs contribuiu para o processo de prestação de contas públicas municipais por parte do Tribunal de Contas dos Municípios do estado da Bahia (TCM-BA)?

\section{Descrição do contexto da pesquisa}

O estudo foi realizado no Tribunal de Contas dos Municípios do estado da Bahia (TCM-BA), na sede em Salvador e nas Inspetorias Regionais de Santo Antonio de Jesus e Juazeiro. A escolha do TCM-BA ocorreu porque o estado da Bahia tem a maior quantidade de municípios dos estados do Nordeste e um Tribunal de Contas específico para o acompanhamento da prestação de contas públicas municipais.

O TCM-BA é a organização pública responsável pelo Acompanhamento da Prestação de Contas Públicas Municipais (APCPM) no âmbito do estado da Bahia. Atualmente, conta com 21 Inspetorias Regionais de Controle Externo (Irces) que fazem o acompanhamento mensal da prestação de contas públicas dos 417 municípios baianos. Essas inspetorias analisam continuamente as prestações de contas encaminhadas pelas prefeituras de sua jurisdição. As informações das prestações de contas são enviadas mensalmente, mas com referência aos fatos ocorridos dois meses antes.

As inspetorias, ao concluírem o exame mensal de cada prefeitura, deixam as informações disponíveis para a sede do Tribunal de Contas, que dá continuidade ao acompanhamento da prestação de contas mensal. Ao término do exercício as prefeituras enviam os dados referentes ao fechamento anual para a sede do Tribunal de Contas, responsável por reunir as informações acumuladas mês a mês, procedentes das inspetorias para fazer a avaliação final do acompanhamento da prestação de contas do exercício (ano anterior). Essa avaliação consiste na elaboração do relatório final do acompanhamento da prestação das contas públicas de cada município, chamado "parecer prévio“, que indica se as contas do gestor público (prefeito) foram: aprovadas, aprovadas com ressalvas ou rejeitadas.

\section{Fundamentação teórica}

\subsection{Uso das TICs nas organizações e no governo}

Sistemas de informação podem ser definidos como um conjunto de cinco componentes: hardware, software, comunicação, pessoas e dados referentes a um dado contexto ou cenário, operando em conjunto. Esses componentes interligados e com um objetivo comum transformam dados em informações, que auxiliam as organizações em suas mais variadas operações, 
desde uma simples consulta a informações até como um suporte em complexos processos de tomada de decisão (O’Brien, 2011; Laudon e Laudon, 2011).

Para Loh (2014), o papel fundamental dos sistemas de informação é unir as tecnologias de informação, ou seja, hardware, software e comunicações à organização, pois são os sistemas de informação os responsáveis por determinar quais dados devem ser coletados e transformados nas informações que serão utilizadas pelas organizações em seus diversos processos.

Na administração pública, o uso das TICs se deu a partir da década de 1960, porém, nesse início, essas tecnologias eram usadas de uma forma muito limitada (Sanchez e Araújo, 2006), sendo comumente utilizadas para o desenvolvimento de sistemas de informação orientados às atividades rotineiras, como folha de pagamento e contabilidade (O'Brien, 2011; Loh, 2014).

A difusão das TICs e a popularização dos computadores pessoais iniciada na década de 1980 promoveram avanços na sociedade, incluindo o setor público, que expandiu a utilização de ferramentas TICs em busca de melhorar a eficiência da administração pública (Raupp e Pinho, 2010). As TICs disponibilizam ferramentas que melhoram os processos de trabalho e facilitam a automação de rotinas repetitivas, a captação de dados na origem, a verificação e correção de erros no instante da captação dos dados, o armazenamento desses dados para uso posterior (Zamot, 2003), e possibilitam efetuar cruzamento de dados em diferentes situações e com vários períodos (Castells, 2002).

Aliada a isso, a crescente popularização da internet nas duas últimas décadas promoveu uma revolução nos meios de informação. Iniciativas de governo eletrônico (e-gov) podem ser encontradas em quase todos os programas de modernização das democracias ocidentais. No século XXI, a globalização está criando uma oferta de iniciativas e demandas que estão colocando forte pressão sobre os governos em todo o mundo para mudar e inovar as modalidades de relacionamento entre suas burocracias e os cidadãos (Ocde, 2003; Bonsón et al., 2012).

Assim, segundo Bonsón e colaboradores (2012), a utilização de sistemas de informação, em conjunto com as facilidades da Web 2.0, potencialmente oferece às organizações públicas importantes benefícios, como melhoria de transparência e de participação do cidadão.

\section{2 prestação de contas públicas}

De acordo com Bresser-Pereira e Spink (2005), o objetivo da nova administração pública é construir um Estado democrático, que responda às necessidades de seus cidadãos, para que seja possível aos políticos fiscalizarem o desempenho dos burocratas e estes sejam obrigados por lei a lhes prestar contas, bem como para que os eleitores possam fiscalizar o desempenho dos políticos e estes também sejam obrigados, por lei, a lhes prestar contas.

A administração pública, tal qual a administração de empresas, é um processo de tomada de decisões sobre objetivos e utilização de recursos. O processo é composto pelas funções de planejamento, organização, direção e controle. A primeira das funções significa e envolve a necessidade de evitar o improviso. A organização trata da integração e da estruturação de 
recursos disponíveis. A direção está relacionada com o comando e tem a responsabilidade de execução das propostas ou "fazer as coisas acontecerem". Para Castro (2008), o controle, como última fase do processo, deve assegurar que os resultados do que foi planejado, organizado e dirigido se ajustem aos objetivos previamente estabelecidos. No contexto do Estado, o controle externo da administração pública é de responsabilidade dos Poderes Legislativos nas esferas de governo federal, estadual e municipal, auxiliados pelos Tribunais de Contas. Assim, nas administrações municipais o controle externo é exercido pelas câmaras de vereadores com o auxílio do Tribunal de Contas (Siraque, 2005).

A existência do primeiro tribunal de contas no Brasil data mais de um século e, entre idas e vindas, houve uma significativa expansão em sua missão: passou, com a Constituição de 1988, a não exercer apenas o controle contábil, financeiro e orçamentário exclusivamente sob a ótica da legalidade, mas, segundo Costa (2005), também teve outorgada a competência para fiscalizar aspectos operacionais e patrimoniais, quanto à legitimidade e à economicidade das despesas realizadas.

Os tempos modernos, nos estados democráticos de direito, trouxeram para o âmbito da administração pública o dever de prestar contas para todo aquele que assume o poder público (Pereira, 2010).

Segundo Platt Neto e colaboradores (2007), as entidades que compõem a estrutura da administração pública brasileira são obrigadas, pela Constituição Federal (CF), a prestar contas sobre o uso de recursos públicos e a respeitar o princípio da publicidade, entre outros princípios da administração pública. Contas públicas abrangem todos os registros e demonstrativos produzidos, publicados ou não, concernentes ao passado, presente e futuro, relativos ao uso dos recursos públicos.

Para o acompanhamento da publicidade das contas e da prestação de contas públicas, os Tribunais de Contas se utilizam de outros instrumentos legais, entre eles, a Lei $\mathrm{n}^{\circ}$ 4.320/1964, a Lei oํ 9.755/1998 e a Lei Complementar no 101/2000 para desempenhar suas atribuições (Brasil, 1997, 1998 e 2000). Na esfera federal, a competência é do Tribunal de Contas da União, nas esferas estadual e municipal, a competência é dos Tribunais de Contas de cada estado, e onde existir Tribunal de Contas do(s) Município(s), é competência deste(s) na esfera municipal.

Para Silva (2008), a prestação de contas pode ser definida como o processo pelo qual, dentro dos prazos estipulados, o responsável tem a obrigação de comprovar, perante o órgão competente, a utilização, o emprego ou a movimentação dos bens, numerários e valores que lhe foram confiados. De acordo com o mesmo autor, o processo de prestação de contas deve abranger os componentes essenciais, que permitam que os entes responsáveis pelos controles externo e interno acompanhem e fiscalizem o que se refira aos aspectos orçamentários e financeiros.

Os principais entes responsáveis pelo controle externo da prestação de contas dos municípios são os Tribunais de Contas (TCs). Para Rocha (2013), a competência dos Tribunais de Contas para fiscalizar os municípios vai muito além da simples apreciação da gestão orçamentária, patrimonial e financeira, como apreciar se as operações realizadas na execução 
dos orçamentos públicos municipais estão de acordo com as normas constitucionais, legais e regulamentares.

As prestações de contas, para quaisquer circunstâncias em que um cidadão utilize ou esteja responsável por recursos e/ou bens públicos, é fase obrigatória perante um superior imediato, um órgão ou uma entidade repassadora dos recursos. De um lado, há alguém que deve prestar contas, obrigatoriamente, e, do outro, as instâncias de acompanhamento e avaliação da prestação de contas (Pereira, 2010).

\section{Metodologia da pesquisa}

Esta pesquisa é de natureza interpretativista, com abordagem qualitativa, tendo como estratégia o estudo de caso único (Yin, 2005; Bardin, 2006; Richardson et al., 1999), descritivo, com o propósito de analisar a contribuição do uso de TICs no Acompanhamento da Prestação de Contas Públicas Municipais (APCPM) por parte de um Tribunal de Contas, e tem como unidade de análise a transformação provocada pela adoção de TICs no Acompanhamento da Prestação de Contas Públicas Municipais feitas por um Tribunal de Contas.

A pesquisa foi realizada entre outubro de 2012 e janeiro de 2013, sendo desenvolvida em duas etapas: a primeira etapa consistiu de uma pesquisa na sede do Tribunal de Contas, que envolveu pesquisa documental e entrevistas semiestruturadas com 15 membros internos do tribunal envolvidos com o processo de prestação de contas públicas. Durante os contatos na sede do Tribunal, surgiu a indicação das inspetorias para a segunda etapa.

A segunda etapa ocorreu em duas inspetorias, Santo Antonio de Jesus e Juazeiro, também efetuada por meio de pesquisa documental e entrevistas semiestruturadas com três membros responsáveis pelo envio das contas públicas ao tribunal. Em cada Inspetoria Regional de Controle Externo (Irce) a pesquisa foi feita em duas fases. A primeira fase na própria inspetoria e a segunda fase na(s) prefeitura(s) indicada(s) pelo Inspetor Regional.

\section{Coleta e análise dos dados}

Na coleta de dados, tanto nas entrevistas quanto nos documentos selecionados, a busca de informações sobre o APCPM referente ao período anterior ao ano de 1998 denominou-se fase Pré-implantação das TICs; e, entre 1998 e 2010, chamou-se fase Pós-implantação das TICs.

\subsection{APCPM pré-implantação das TICs}

O período de Acompanhamento da Prestação de Contas Públicas Municipais na fase pré-implantação das TICs abrange desde a criação do Tribunal de Contas dos Municípios do estado da Bahia (TCM-BA), em 1971, até 1998. 
$\mathrm{Na}$ análise dos dados desse período, destacaram-se, inicialmente, os relatos do conselheiro de experiência mais antiga no Tribunal, e sua afirmação de que a aplicação de recursos públicos municipais não era acompanhada e as prestações de contas não eram sequer analisadas, até a criação do Tribunal de Contas dos Municípios (TCM). O segundo destaque refere-se ao que foi mencionado por um analista de Controle Externo ao descrever o percurso deste processo: desde a criação do TCM-BA, segundo Sampaio Filho (2000), ocorrida em 1971, até 1981, a documentação gerada nas prefeituras ia para o Tribunal, que examinava essa documentação por amostragem e gerava um Relatório Técnico (RT), o qual era encaminhado para o gabinete de conselheiro, que dava origem ao voto, relatório preliminar do parecer prévio. Essa documentação era composta por um conjunto de documentos, relacionados em resoluções encaminhadas pelo Tribunal aos gestores municipais em cada exercício. Após o exame das contas, o tribunal devolvia toda a documentação recebida para as prefeituras.

O Conselheiro dividiu a história do Tribunal de Contas em duas etapas. A primeira etapa foi definida como a da necessidade de criação de um tribunal de contas especializado na análise da aplicação de recursos públicos municipais. E a segunda etapa, a partir de 1998, foi a informatização do Tribunal, que será tratada mais adiante na subseção 5.2.

De acordo com o conselheiro, a primeira etapa se prolongou até quando o TCM conseguiu informatizar os seus trabalhos. Nessa época, com os recursos disponíveis, havia uma dificuldade enorme de emissão de pronunciamentos sobre a legalidade ou não da aplicação dos recursos públicos. Como os pareceres prévios eram emitidos para os 417 municípios do estado da Bahia, o Tribunal observava apenas quatro ou cinco aspectos de natureza formal, com base na Lei Federal no 4.320/1964 (Brasil, 1997).

As constatações mencionadas pelo conselheiro estão de acordo com a proposta de reforma da administração pública (Bresser-Pereira e Spink, 2005), com o controle como última fase do processo administrativo, assegurando que os resultados daquilo que foi planejado, organizado e dirigido se ajustavam aos objetivos previamente estabelecidos (Castro, 2008) e com o controle externo da administração pública, que é responsabilidade dos Poderes Legislativos auxiliados pelos Tribunais de Contas (Siraque, 2005). Quanto ao relato do analista de Controle Externo, observou-se que o exame das prestações de contas era todo feito manualmente e de forma "artesanal", sem utilização de nenhum recurso tecnológico, corroborando a descrição do conselheiro de que apenas aspectos formais eram analisados.

Conforme explica o analista de Controle Externo, a partir de 1981 o Tribunal começou a descentralizar a análise das prestações de contas, com a criação de Inspetorias Regionais de Controle Externo (Irces) nos municípios de maior importância política. Inicialmente, foram criadas as primeiras inspetorias: Salvador, Itabuna e Santo Antonio de Jesus. Nessa época, se encaminhavam para as inspetorias formulários impressos em mimeógrafos, que eram preenchidos com base na documentação recebida das prefeituras. Esses formulários eram enviados para a sede, pelo correio, à medida que eram finalizados. Tais formulários compunham um conjunto de relatórios denominados Relatórios Mensais (RM), Relatórios Mensais Complementados (RMC), Relatórios Anuais (RA) e notificações. Estas últimas eram os avisos encaminhados aos gestores das não conformidades identificadas na documentação. Esse conjunto 
de relatórios formava a base para que, na sede do TCM, fossem elaborados os relatórios finais da área técnica, que davam origem aos pareceres prévios. Parecer prévio é o relatório final do Tribunal relativo à análise da prestação de contas de cada município.

A partir dessa explicação, observou-se que o TCM responsabilizava-se pela extração das informações necessárias para o APCPM a partir da documentação encaminhada pelas prefeituras. As informações mais relevantes para a análise das prestações de contas eram o acompanhamento dos índices constitucionais da educação e Fundef, e a análise das demonstrações contábeis exigidas pela Lei no 4.320/1964 (Brasil, 1997); por exemplo, a execução orçamentária (o orçamento), a aplicação dos recursos de receita e despesas, os créditos adicionais, a documentação de receita e de despesa, os balancetes, os processos de pagamentos (licitações, contratos, empenho, liquidação) e pagamento, conforme resolução do Tribunal para o exercício em questão.

Constatou-se que a documentação apresentada estava de acordo com os registros e demonstrativos constantes no artigo de Platt Neto e colaboradores (2007), e que, a partir da criação das inspetorias, em 1981, os formulários adquiriram o primeiro formato padronizado, apesar de serem preenchidos tanto à mão quanto datilografados.

A elaboração dos relatórios de acompanhamento da prestação de contas era uma tarefa lenta e trabalhosa. Até 1981, os recursos humanos utilizados, de nível médio, eram entre 18 e 20 agentes de controle externo e, de nível superior, também entre 18 e 20 técnicos de controle externo, hoje analistas de controle externo. Depois, com a criação das inspetorias, a equipe incluía entre três e cinco pessoas, inclusive os inspetores, com nível de instrução médio ou superior.

Os recursos materiais disponíveis eram, principalmente, mimeógrafo, máquina de escrever e calculadoras manuais com bobinas de papel.

Até 1988, o tribunal não tinha prazo para concluir o acompanhamento das prestações de contas anuais dos municípios. O TCM examinava contas de dois, três anos anteriores. A Constituição estadual em 1989 determinou prazo para conclusão do acompanhamento das prestações de contas anuais pelo tribunal (Bahia, 1989, 2012). A partir de então, os prazos passaram a ser obedecidos, assim como novas normas mais claras foram estabelecidas para a prestação de contas por parte dos gestores municipais. Em consequência, novas informações passaram a fazer parte do acompanhamento das prestações de contas anuais (Silva, 2008; Pereira 2010).

De acordo com os coordenadores e inspetores entrevistados, a partir da promulgação da Constituição Federal, em 1988, o Tribunal começou a verificar o que determinava os índices constitucionais na aplicação dos recursos em educação com $25 \%$, saúde com $15 \%$ e pessoal com 54\% para prefeituras. Na análise da prestação de contas, além dos índices constitucionais, eram considerados os seguintes elementos: a execução orçamentária, todos os comprovantes de receita e despesa, os balancetes, os processos de pagamentos (licitações, contratos, empenho, liquidação e pagamento). A relação de documentos que deveria ser enviada na prestação de contas constava nas resoluções do Tribunal para cada exercício. 
A partir de 1992, os formulários mimeografados foram gradativamente substituídos por formulários pré-impressos por computador. Esses formulários pré-impressos por computador (em três vias com carbono) tornaram-se o marco inicial de utilização da tecnologia da informação no APCPM, embora de forma elementar. Os formulários preenchidos nas Irces eram padronizados e os relatórios gerados na sede tinham mais flexibilidade, pois poderiam conter comentários do analista em assuntos que julgasse pertinente. Esses formulários e relatórios serviram de base para o desenvolvimento do primeiro sistema de informação voltado para o APCPM, o Sistema de Acompanhamento da Execução Orçamentária (Saesc), cuja utilização ocorreu a partir de 1998.

A elaboração do RM na inspetoria, de acordo com o inspetor, levava em consideração o fato de que o técnico necessitava pegar a documentação, somar, fazer as conferências iniciais, somar receita, somar despesa, conferir os processos, conferir os dados em contato com o balancete, separar e conferir se os dados que estavam lançados com saúde e educação-coincidiam e se estavam compatíveis com os documentos apresentados. Esse trabalho absorvia em torno de 10 dias de trabalho, que variava em função da quantidade de processos de pagamentos e da qualidade e complexidade das informações desses processos. Na sede, a elaboração do Relatório Anual (RA) levava, em média, seis dias, e o Pronunciamento Técnico (PT), em média, três dias.

De 1988 (após a promulgação da Constituição Federal) até a implantação do primeiro sistema de informação voltado para a atividade-fim, em 1998, os recursos humanos eram, qualitativamente, metade de nível médio e metade de nível superior, exceto os sete auditores formados em nível superior. A quantidade de funcionários técnicos e agentes nas inspetorias girava em torno de 130 pessoas e a quantidade de técnicos, na sede, era em torno de 21 .

Os recursos materiais eram os mesmos de antes da Constituição Federal. Geralmente, não se conseguiam cumprir os prazos para os relatórios das inspetorias porque os recursos eram limitados para o volume de serviços. O prazo constitucional, após 1988, para a prestação de contas do mês de dezembro, foi fixado até março do ano seguinte. Esses prazos passaram a ser cumpridos com flexibilidade, contanto que todas as contas fossem apreciadas (prefeituras) e julgadas (câmaras e autarquias) até o dia 15 de dezembro do exercício seguinte.

O Tribunal conseguia fazer o julgamento das contas, de acordo com os conselheiros entrevistados, porque os votos (preliminar dos pareceres prévios) eram de duas a três páginas, no máximo, com análise focada em poucas informações, basicamente nas conformidades legais. Se fosse como hoje, em torno de 20 páginas, seria impossível cumprir os prazos com os recursos disponíveis na época.

O parecer prévio final refletia o conteúdo das informações extraídas da documentação e analisadas, apenas do ponto de vista de conformidade com a Lei no 4.320/1964 (Brasil, 1997), até a promulgação da Constituição Federal de 1988. A partir daí, novos critérios foram sendo acrescentados, entre eles os índices constitucionais que as prefeituras teriam de atender quanto à aplicação dos recursos públicos alocados aos municípios (Brasil, 1988).

Com relação à confiabilidade e necessidade de complementação das informações para elaboração do parecer prévio, tanto os entrevistados do Tribunal de Contas, quanto os das 
prefeituras consultadas, foram convergentes ao afirmarem que as informações enviadas eram suficientes e confiáveis para acompanhamento, de acordo com Lei oㅡ 4.320/1964, o que chamavam de auditoria de conformidade. Contudo, precisava-se buscar informações adicionais para explicar as irregularidades que não eram sanadas na inspetoria e havia, nesses casos, notificação ao gestor.

Os resultados do julgamento anual das prestações de contas públicas municipais (decisão) extraídos da documentação interna do tribunal no período 1990 a 1998 estão apresentados na tabela 1. Em relação à quantidade de contas rejeitadas antes das TICs, um dos conselheiros entrevistados mencionou o seguinte:

O número de rejeição de contas era bem menor antigamente. Justamente por falta de informações e também por carência de legislação e regras específicas mais voltadas para esse fim. Depois, veio Fundef (hoje, Fundeb). Em 2000 veio LRF, depois veio a Saúde, as alterações na Constituição, na parte de subsídios mesmo, que a Constituição era mais frouxa, houve alterações sobre remuneração. Quanto a números, eu não sei se chegava a 10\%, mas, não posso informar com segurança.

A tabela 1 apresenta as contas rejeitadas no período 1990-98.

Tabela 1

Resultados do julgamento das contas no período 1990 a 1998

\begin{tabular}{|ccccccc|}
\hline \multirow{2}{*}{ Ano } & \multicolumn{5}{c|}{ Decisão } \\
\cline { 2 - 7 } & Sem decisão & Aprovadas & Aprovadas com Ressalvas & Rejeitadas & Outras & Total Geral \\
\hline 1990 & 128 & 159 & 126 & 2 & 415 \\
1991 & 83 & 236 & 95 & 1 & 415 \\
1992 & 59 & 238 & 111 & 7 & 415 \\
1993 & 42 & 339 & 34 & & 415 \\
1994 & 1 & 35 & 336 & 32 & 2 & 415 \\
1995 & 36 & 337 & 38 & 7 & 415 \\
1996 & & 9 & 393 & 63 & 6 & 415 \\
1997 & & 5 & 379 & 30 & 2 & 415 \\
1998 & 1 & 3 & & & & 415 \\
\hline
\end{tabular}

Fonte: Elaborada pelos autores a partir da documentação do TCM-BA.

Ao analisar a tabela 1, observou-se que o percentual de rejeição de contas ultrapassou os 10\% nos dois anos seguintes à promulgação das Constituições Federal e Estadual, quando houve uma grande elevação de contas rejeitadas devido, principalmente, à falta de adaptação das prefeituras perante as novas exigências legais. Em 1992 e 1996, também foi ultrapassado o percentual de $10 \%$ de contas rejeitadas, em função de ser ano de eleições municipais, quando há uma tendência de aumento das rejeições, de acordo com o estudo de Pereira (2010). 
Ao se observar o gráfico 1, que mostra os dados da tabela 1, nota-se que as contas rejeitadas apresentam uma tendência descendente e as aprovadas apresentaram característica semelhante no período. Porém, as aprovadas com ressalvas apresentaram uma tendência ascendente no período.

Gráfico 1

Julgamento das contas no período de 1990 a 1998

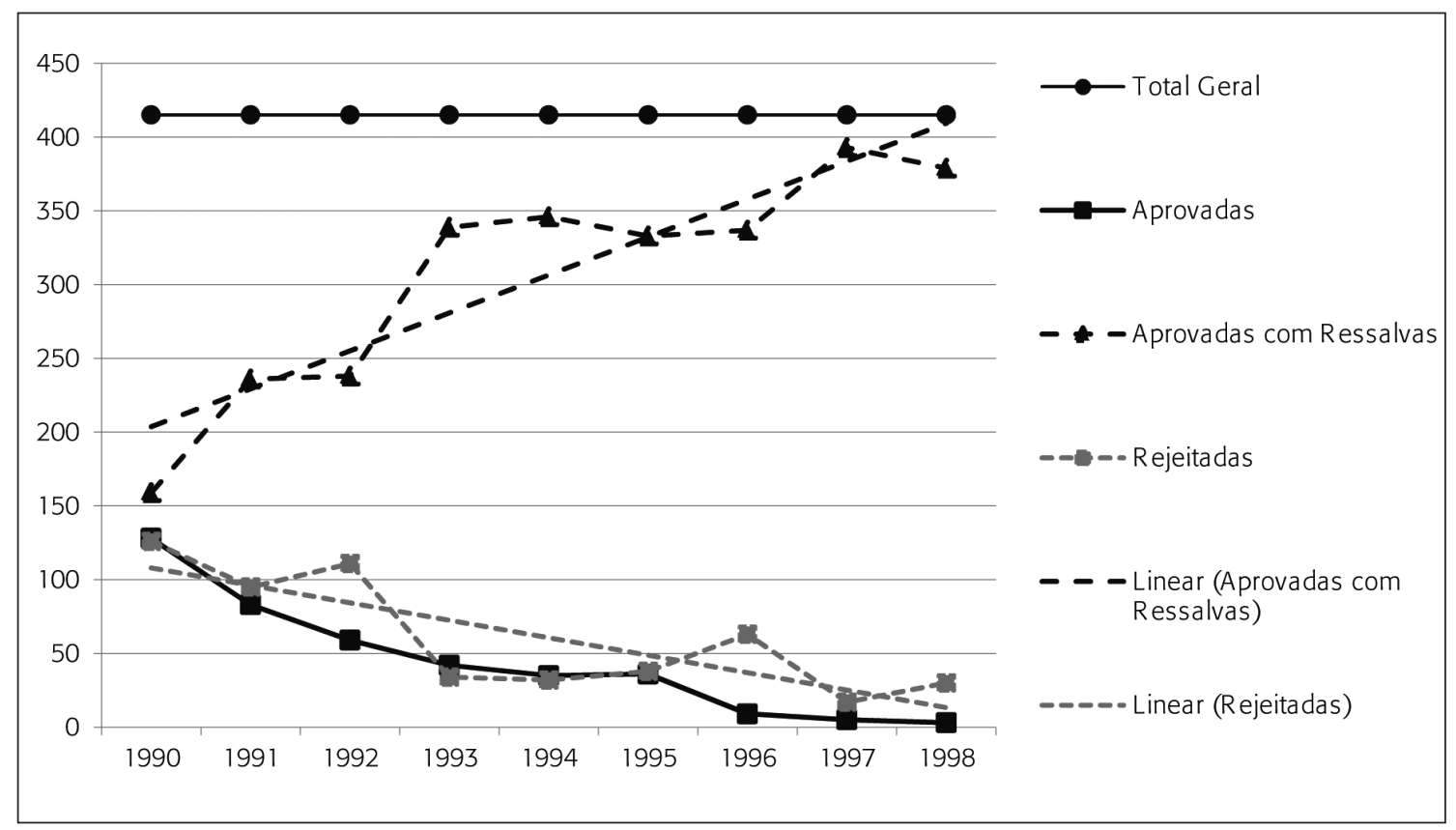

Fonte: Elaborado pelos autores a partir da tabela 1.

De acordo com os relatos dos entrevistados, o APCPM feito até a Constituição Federal de 1988 baseava-se exclusivamente nos aspectos de natureza formal quanto à sua legalidade (Costa, 2005). A partir de 1989, a Constituição do Estado da Bahia estabeleceu normas mais claras para atuação do Tribunal de Contas dos Municípios (Bahia, 1989; Bahia, 2012).

Nos anos seguintes à promulgação da Constituição, a análise da prestação de contas passou a ter mais requisitos para serem verificados, como os índices constitucionais. Contudo, o acompanhamento da prestação de contas era limitado à verificação da documentação recebida das prefeituras, porque o tribunal não tinha recursos adequados para fazer cruzamento de dados e confrontar aplicações (gastos) semelhantes entre municípios de mesmo porte e com características idênticas. Assim, os entrevistados internos do tribunal argumentaram que em torno de $88 \%$ das prefeituras baianas faziam suas prestações de contas para atender os requisitos legais, mas muitos gestores não davam importância ao tribunal, principalmente, pela falta de regras específicas. Como mencionou um dos conselheiros entrevistados: 
Eu diria que a repercussão da atuação do tribunal só veio acontecer depois do uso da informática. Porque, depois do uso da informática o tribunal passou a dispor de elementos para dar informação à sociedade. Então, a repercussão cresceu. Você veja Salvador. Salvador só veio a ter conta rejeitada depois da informatização. E aí, o papel do Tribunal de Contas hoje perante a comunidade de Salvador é reconhecido.

Assim, completou-se a análise dos dados relativos ao primeiro objetivo específico. A próxima subseção trata da análise do processo de prestação de contas após a implantação das TICs.

\subsection{APCPM pós-implantação das TICs}

O período de Acompanhamento da Prestação de Contas Públicas Municipais pós-implantação das TICs foi iniciado em 1998. Foi a continuação do processo de adoção de TICs nos trabalhos do controle externo do Tribunal, que, além de auxiliar na modernização dos processos internos, seguia a ideia de globalização, que apresentava iniciativas e novas demandas e colocava forte pressão sobre o governo para mudar e inovar o processo de prestação de contas dos tribunais e inovar, também, o modo como se relacionavam as organizações do governo com os cidadãos (Ocde, 2003; Bonsón et al., 2012), e, no caso do tribunal, o relacionamento com os seus jurisdicionados.

A implantação do Sistema de Acompanhamento da Execução Orçamentária (Saesc), em 1998, foi o destaque da utilização das TICs no Tribunal de Contas, embora já se fizesse uso de computadores, mas de forma muito incipiente, com poucos sistemas em uso. Os principais sistemas informatizados eram a folha de pagamento, o Sistema de Controle de Contas (Sicco), os programas de formatação e impressão dos formulários e o pacote Office da Microsoft.

No período 1992-97, iniciaram-se a contratação de servidores e a aquisição de microcomputadores e impressoras. Nos primeiros sete anos da década de 1990, o uso de TICs no Tribunal era muito limitado, semelhantemente aos primeiros anos de utilização em outras organizações públicas, como mencionaram Sanchez e Araújo (2006) em seu trabalho. O primeiro sistema implantado no TCM era focado na atividade meio — folha de pagamento — , similarmente às organizações públicas, no início de utilização de ferramentas TICs (Prodesp, 1970).

As informações mais relevantes para a análise da prestação de contas continuam sendo as mesmas exigidas antes das TICs. Entretanto, com a implantação do Saesc, os formulários variavam na quantidade de folhas em função da quantidade, qualidade e complexidade da documentação encaminhada pelas prefeituras ao Tribunal, e o preenchimento desses formulários era feito diretamente na tela do computador.

A partir de 1998, com o uso de ferramentas TICs, o Tribunal passou a contar com mais informações sistematizadas para a análise das prestações de contas, como a comparação de gastos numa mesma atividade entre municípios de mesmo porte, o que tornou o acompanhamento da prestação de contas mais eficaz. 
Depois da implantação efetiva de ferramentas TICs, a elaboração dos relatórios passou por duas fases: com o Saesc e com o Sistema de Informação de Gestão e Auditoria (Siga). Com o Saesc os técnicos examinavam a documentação, inseriam os dados e o sistema fazia as contas. Com o Siga o gestor (prefeitura) encaminha os dados via internet, o sistema audita, faz as contas e gera as irregularidades. Irregularidades que agora são denominadas de achados (são as não conformidades), geradas pelo Siga.

O tempo para elaboração do RM continuou o mesmo com ou sem TICs, pois a redução de tempo foi compensada com o aumento das informações requeridas. Para a elaboração do RMC, com o Saesc, precisava-se de três dias e, com o Siga, passou-se para quatro dias (aumentou o tempo, pois se tornou necessário justificar cada item do relatório).

A partir do exercício de 2000, as legislações passaram por diversas alterações. Além do cumprimento dos índices constitucionais já citados, os jurisdicionados passaram a ser obrigados a aplicar determinados percentuais na área de Saúde, Despesa de Pessoal e no Fundeb. Consequentemente, o tribunal passou a ter mais itens a serem verificados na prestação de contas, o que o levou à utilização de mais ferramentas TICs para atender essas demandas legais, e com potencial de oferecer benefícios como melhoria de transparência e de participação do cidadão (Bonsón et al., 2012).

De 2010 em diante, o Tribunal mudou internamente a sistemática de prestação de contas: permaneceu o envio da documentação, mas os jurisdicionados passaram a ter a obrigatoriedade de transmitir os dados via internet pelo sistema Siga. A implantação desse sistema trouxe, na percepção de um conselheiro, a possibilidade de fazer cruzamento dos dados declaratórios informados pelas prefeituras com os dados que o tribunal dispunha de quanto cada município recebeu de recursos do Fundeb, royalties, Cide e outros. Esse procedimento melhorou os processos de trabalho e facilitou a automação de rotinas repetitivas e a captação de dados na origem, bem como permitiu fazer cruzamento de dados em diferentes situações e vários períodos (Castells, 2002; Zamot, 2003). Como mencionou o conselheiro, o Tribunal passou da fase cartorial para a fase de confrontação entre aquilo que o município declarava e o que ele efetivamente realizava.

Os relatórios RA e RT foram substituídos pelos relatórios Cientificação e Relatório de Prestação de Contas Mensal, que, além de contemplar as irregularidades identificadas nas análises das prestações de contas, contemplam informações mais abrangentes que os RA e RT.

Em média, na sistemática anterior a 2010 (antes do Siga), um analista levava até seis dias para finalizar uma prefeitura (RA e RT), em condições normais. Na fase atual (com o Siga), em média, um técnico pode levar até três dias para concluir a análise.

Os recursos humanos de nível médio, dedicados ao acompanhamento das prestações de contas, foram reduzidos, e os de nível superior aumentaram. Os auditores permanecem os mesmos. Na sede eram 21 analistas e nas inspetorias 130 analistas e agentes, os mesmos utilizados antes das TICs. Em relação aos recursos materiais, são os mesmos, exceto as ferramentas TICs que aumentaram, como mostra a figura 1. Além dos equipamentos e sistemas de informação da sede, cada inspetoria tem nobreak, servidor, estações de trabalho e impressora. 
Figura 1

Rede de dados corporativa do TCM-BA

\section{Ambiente da Rede de Dados Corporativa - TCM-BA}

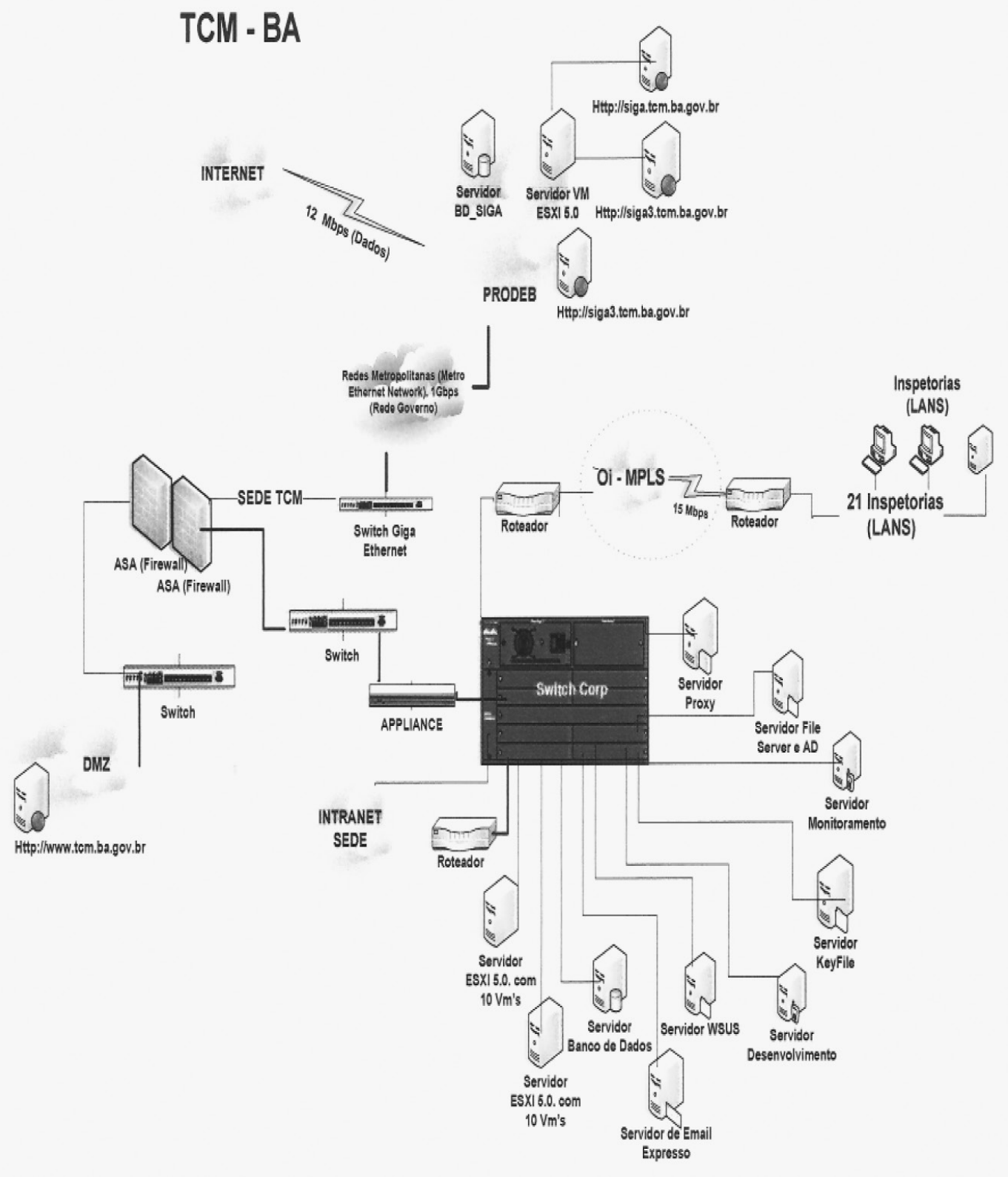

Fonte: Diretoria de Informática do TCM-BA. 
A rede de dados corporativa do TCM-BA é formada por vários servidores na sede, servidores do sistema Siga na Empresa de Processamento de Dados do Estado da Bahia (Prodeb) e um servidor em cada uma das 21 inspetorias. Essa rede está conectada à internet, que tem o Firewall (ASA) para proteger tanto a integridade dos dados na rede como a confidencialidade deles, e o Servidor Proxy para gerenciar a conexão da rede interna do Tribunal à internet, impondo políticas de acesso e barreiras de segurança. A difusão das TICs, as facilidades proporcionadas pela internet e a rede de dados corporativa do TCM-BA promoveram avanços no Tribunal, que expandiu a utilização de ferramentas TICs na busca de melhoria da eficiência no processo de análise da prestação de contas (Raupp e Pinho, 2010).

De acordo com os inspetores, os prazos para os relatórios das inspetorias têm sido geralmente cumpridos; quanto aos relatórios da Sede, os entrevistados corroboram que continuam os mesmos que antes das TICs para o Saesc e se reduziram com a implantação do Siga. Quanto à qualidade dos relatórios elaborados nas inspetorias, as pendências, na forma de irregularidades, aumentaram. O sistema tornou a análise mais refinada e exigiu mais do gestor. Houve uma evolução na metodologia, na forma de acompanhar a conformidade da aplicação dos índices constitucionais. Já os relatórios elaborados na sede continuam confiáveis, mas são complementados com novas informações.

Em relação ao cumprimento dos prazos para o julgamento das contas, mesmo com pareceres prévios variando de 12 a 20 folhas, de acordo com os conselheiros entrevistados, os prazos têm sido rigorosamente cumpridos. Os relatórios que servem de base para o parecer prévio final apresentam-se mais confiáveis. Hoje, com a utilização do sistema Siga, a informação só vem incompleta por omissão do gestor. Mas, se ele não for omisso, o Tribunal tem as informações que precisa para trabalhar.

O resultado do julgamento anual das prestações de contas públicas municipais (decisão) extraído da documentação interna do Tribunal no período 1999 a 2010 está apresentado na tabela 2, sendo este último ano, o ano da implantação do Siga para o APCPM.

Tabela 2

Resultados do julgamento das contas no período 1999 a 2010

\begin{tabular}{|ccccccc|}
\hline \multirow{2}{*}{ Ano } & \multicolumn{7}{c|}{ Decisão } \\
\cline { 2 - 7 } & Sem decisão & Aprovadas & Aprovadas com Ressalvas & Rejeitadas & Outras & Total Geral \\
\hline 1999 & 1 & 6 & 313 & 95 & 0 & 415 \\
2000 & 2 & 3 & 284 & 122 & 6 & 417 \\
2001 & 0 & 5 & 364 & 47 & 1 & 417 \\
2002 & 0 & 6 & 341 & 67 & 3 & 417 \\
2003 & 0 & 311 & 95 & 8 & 417 \\
2004 & 1 & 5 & 248 & 151 & 12 & 417 \\
2005 & 0 & 4 & 342 & 98 & 3 & 417 \\
2006 & 0 & 1 & 284 & 125 & 5 & 7 \\
2007 & 0 & 1 & 215 & 182 & 7 & 417 \\
2008 & 12 & 1 & 343 & 68 & 6 & 417 \\
2009 & 0 & 0 & 336 & 76 & 4 & 417 \\
2010 & 1 & 0 & & & 417 \\
\hline
\end{tabular}

Fonte: Elaborada pelos autores a partir da documentação do TCM-BA. 
Conforme a tabela 2, observa-se que houve um crescimento de contas rejeitadas, número maior do que antes da utilização de sistemas de informação no APCPM. A explicação para o aumento da rejeição de contas, na opinião dos conselheiros entrevistados, ocorreu em função da adoção de TICs permitir um aprofundamento maior e uma análise mais cuidadosa das regras e princípios estabelecidos. Essa tendência de crescimento de contas rejeitadas das prefeituras também foi observada no estudo de Pereira (2010).

O gráfico 2 mostra os números da tabela 2 .

Gráfico 2

Julgamento das contas no período de 1999 a 2010

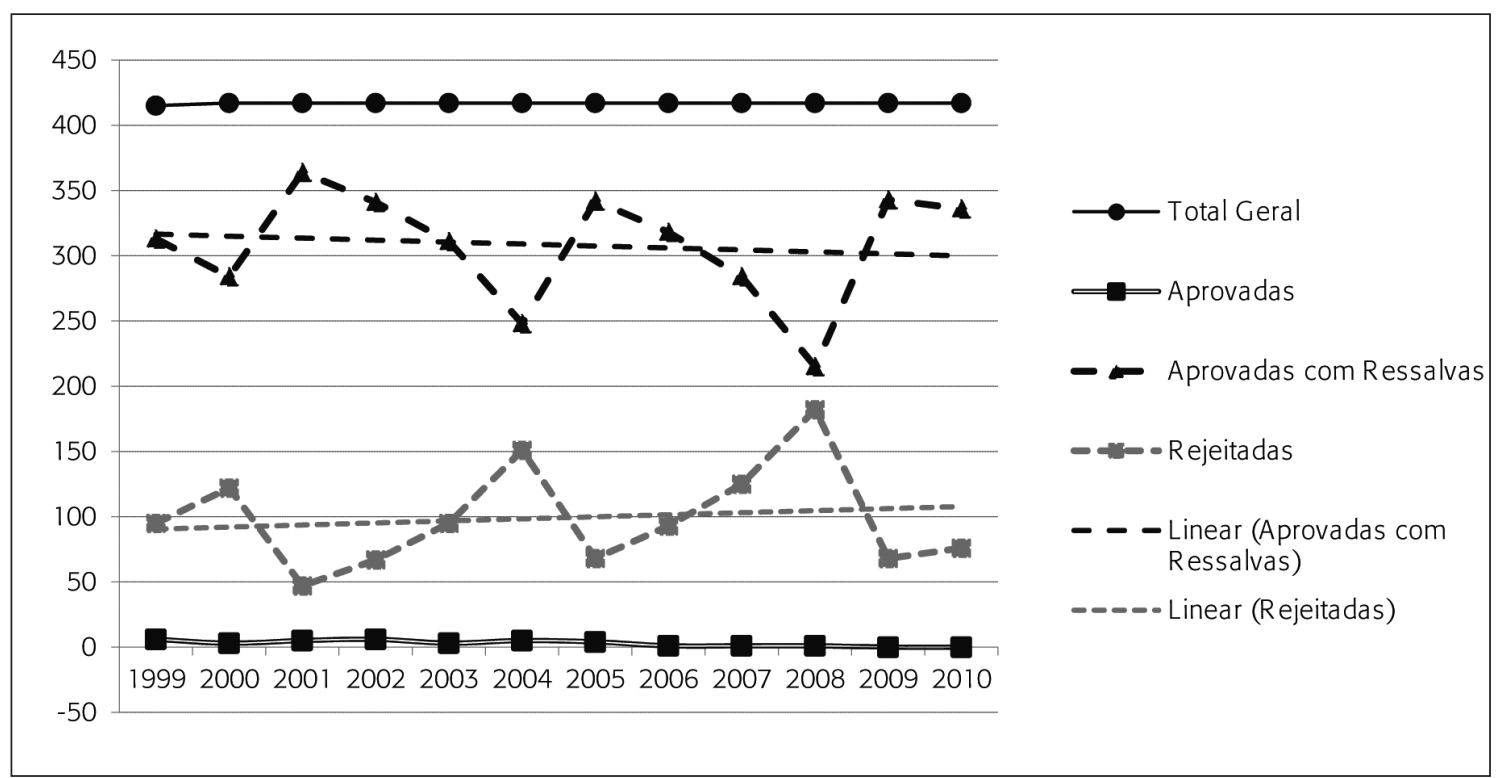

Fonte: Elaborado pelos autores a partir da tabela 2.

Observando-se esse gráfico, nota-se que nos quadriênios 2001-04 e 2005-08 ocorreu um aumento gradativo das contas rejeitadas no $2^{\circ}, 3^{\circ}$ e $4^{\circ}$ ano de cada quadriênio e uma redução drástica no início do quadriênio seguinte; a maior quantidade de contas rejeitadas ocorreu no último ano desses quadriênios, que coincide com o ano de eleição municipal. $\mathrm{O}$ inverso ocorreu com as contas aprovadas com ressalvas.

Antes das TICs, era comum uma média de 10 a 15\% dos municípios não apresentarem a prestação de contas. Os dados mais recentes indicam que esse percentual caiu para menos de $1 \%$. Hoje, há mais respeito dos gestores pelo TCM, principalmente, devido às consequências previstas na legislação. Contudo, um dos entrevistados opinou que há gestores municipais que continuam indiferentes ao julgamento do TCM, porque as contas rejeitadas pelo TCM podem ser aprovadas pela Câmara de Vereadores. Isto pode levar à perda da eficácia da Lei de Ficha Limpa e tornar o julgamento do TCM inócuo. 


\section{Considerações finais}

O foco deste estudo foi examinar como as ferramentas TICs foram utilizadas e identificar a contribuição das mesmas no APCPM. Consideraram-se, como ponto de partida, as referências teóricas, agrupadas em categorias de análise correspondentes aos objetivos específicos, que serviram de base para a coleta dos dados. Isto permitiu a compreensão e análise da influência da adoção de TICs no processo de prestação de contas.

Constatou-se que desde a fundação do TCM-BA, em 1971, até a promulgação da Constituição Federal em 1988, a análise das prestações de contas se limitava às conformidades legais com base na Lei no 4.320/1964. Nesse período, predominava, entre os gestores, a ideia de que o tribunal era inoperante ou tinha um funcionamento precário. Na realidade, os gestores não davam importância para o tribunal, principalmente, pela ausência de regras claras, tanto para a prestação de contas quanto para aplicar punição a quem não as prestasse.

De 1988 até 1998, a APCPM passou por um processo evolutivo, primeiramente em função das novas exigências legais. Depois, pela reformulação dos formulários e relatórios de acompanhamento da prestação de contas até 1998, quando ocorreu a implantação do primeiro sistema de informações, denominado Saesc, para o APCPM. Com esse sistema, o preenchimento dos formulários, que eram escritos à mão ou datilografados, passou a ser preenchido diretamente na tela do computador pelos técnicos do TCM.

A partir do ano 2000, a legislação passou por diversas alterações e novas informações foram acrescentadas para análise da prestação de contas na área de Saúde, Despesa de Pessoal e Fundeb.

Em 2010, ocorreu a implantação do Siga, por meio do qual o gestor passou a enviar suas informações via internet, de forma declaratória, responsabilizando-se pelas informações enviadas.

Depois da adoção de TICs no APCPM, foi possível um aprofundamento maior e uma análise mais cuidadosa das regras e princípios estabelecidos, como também critérios mais rigorosos foram acrescentados às leis que regem a prestação de contas, o que levou os pareceres prévios a variarem de 12 a 20 folhas.

O julgamento das contas públicas municipais é o resultado final do processo de acompanhamento da prestação de contas. Para fazer o julgamento das contas, denominado parecer prévio, o Tribunal analisa as contas dos municípios de acordo com leis, normas e resoluções inerentes ao processo e faz uso de métodos e tecnologias disponíveis que o auxiliem no cumprimento dessas atribuições.

O presente estudo procurou, à medida do possível, não se distanciar dos caminhos de interesse da administração. Embora não tenham sido focados abertamente temas básicos como planejamento, coordenação, direção e controle, tais elementos estão implícitos nas descrições sobre o APCPM e nos resultados alcançados com adoção de TICs.

Os principais impactos identificados, decorrentes do uso de ferramentas TICs, ocorreram no próprio processo de prestação de contas, no TCM e nas prefeituras. Esses impactos foram relacionados no quadro 1, mostrando o modus operandi do processo antes das TICs e como ficou depois da adoção das mesmas. 


\section{Quadro 1 \\ Principais impactos do uso de TICs no APCPM}

\section{Período pré-TICs}

As inspetorias prospectavam os dados a partir da documentação recebida das prefeituras, preenchiam os formulários e enviavam para a sede via correio. Podiam ocorrer erros de prospecção ou de falta de dados.

2 As inspetorias prospectavam os dados a partir da documentação recebida das prefeituras. Os erros de prospecção e digitação de dados eram corrigidos após verificação pelos técnicos das inspetorias ou pelos gestores municipais.

3 Não era possível fazer cruzamento de informações com os recursos e tempo disponíveis naquela época.

4 Não era possível fazer comparação de gastos com os recursos e tempo disponíveis naquela época.

$5 \quad$ Não era possível melhoria nas correções, pois os relatórios ficavam prontos no limite dos prazos e as orientações eram limitadas às formalidades legais, quando possível.

6 A análise da prestação de contas se limitava basicamente às conformidades legais.

$7 \quad$ O processo era lento, pois a prospecção de dados era feita pelo Tribunal junto à documentação recebida para depois preencher os dados nos relatórios.

8 Os gestores municipais em geral davam pouca importância à prestação de contas. O tribunal era pouco reconhecido pelos gestores municipais.

9 As prefeituras preparavam toda a documentação, enviavam para as inspetorias e buscavam a documentação.
Impacto com Uso das TICs

Transferiu o trabalho de prospecção e digitação de dados feitos pelas inspetorias para as prefeituras e com isso possibilitou que as próprias prefeituras informassem os seus dados referentes à prestação de contas.

Eliminou a redundância (prospectar e digitar os dados nas inspetorias), o retrabalho (preparar, enviar e buscar a documentação) e os erros de transcrição de dados (na prospecção e digitação).

Permitiu cruzamento de informações, identificação automática de irregularidades e maior facilidade de divulgação de informações ao público.

Permitiu comparação de gastos com objetivos similares, entre municípios semelhantes, possibilitando recomendações e correções.

Contribuiu para melhoria na correção e na orientação para aplicação de recursos alocados aos municípios de acordo com as leis, normas e resoluções vigentes.

Aumentou a confiabilidade na análise das prestações de contas com a realização de cruzamento e confrontação de dados e comparação de gastos similares entre municípios semelhantes.

Permitiu mais agilidade na análise das prestações de contas, apesar do crescimento da quantidade de informações a serem analisadas, em função dos novos instrumentos legais.

Possibilitou o aumento do reconhecimento da legitimidade e reputação do TCM junto aos gestores municipais.

Possibilidade de, a partir de 2013, não ser mais necessário o envio da documentação física para as inspetorias pelas prefeituras.

Fonte: Elaborado pelos autores (2013).

As principais contribuições decorrentes do uso de ferramentas TICs ocorreram no próprio processo de prestação de contas, no TCM-BA e nas prefeituras jurisdicionadas. Essas contribuições foram:

จ Transferiu os lançamentos dos dados da prestação de contas do Tribunal para as prefeituras com a implantação do sistema de informação Siga. 
- Eliminou redundância e retrabalho, porque o Tribunal deixou de procurar na documentação as informações necessárias e transcrevê-las para os formulários apropriados.

、 Permitiu cruzamento e confrontação de dados, em função de ter os dados armazenados em seu banco de dados.

- Possibilitou a comparação de despesas entre municípios semelhantes, porque tem as informações de todos os municípios armazenados em seu banco de dados.

จ Contribuiu para melhoria na correção e na orientação para aplicação de recursos aos jurisdicionados dentro das conformidades legais, em função da criação de eventos pelo Tribunal nas principais cidades do estado. Nesses eventos, a administração e seus técnicos mais experientes ministram palestras sobre os temas (legais, contábeis e de TICs) daquele momento.

v Aumentou a confiabilidade na análise das prestações de contas, que foi além das conformidades legais, com a realização de cruzamento e confrontação de dados e comparação de gastos similares entre municípios semelhantes.

v Permitiu mais agilidade no processo, em função do uso de sistemas de informação integrados.

v Possibilitou o aumento do reconhecimento da legitimidade e reputação do TCM junto aos gestores municipais, em função da definição de critérios mais rigorosos e da utilização de ferramentas TICs na análise da prestação de contas.

v Abriu perspectivas para melhorias contínuas no processo, como não ser mais necessário o envio da documentação física para as inspetorias pelas prefeituras a partir de 2013, em função da implantação do Siga e pelo aumento das auditorias in loco.

v As contas rejeitadas apresentaram uma tendência quadrienal de aumento e consequente queda de contas aprovadas com ressalvas. No ano seguinte, observou-se que essa tendência quadrienal se inverteu e ocorreu um aumento de contas aprovadas com ressalvas e consequente queda de contas rejeitadas. As contas aprovadas (sem ressalvas) caíram de seis para zero no mesmo período.

\section{Referências}

ABRUCIO, Fernando L.; LOUREIRO, Maria R. Finanças públicas, democracia e accountability. In: BIDERMAN, Ciro; ARVATE, Paulo (Org.). Economia do setor público. Rio de Janeiro: Campus, 2004. p. 75-102.

AGOSTINETO, Raquel C.; RAUPP, Fabiano M. Prestação de contas por meio de portais eletrônicos: um estudo em câmaras municipais da Grande Florianópolis. Revista Universo Contábil, v. 6, n. 3, p. 64-79, jul./set. 2010. 
BAHIA. Constituição do Estado da Bahia, atualizada até a Emenda Constitucional no 14, de 17/06/2010. Edição de 28/08/2012. Disponível em: <www.al.ba.gov.br>. Acesso em: 17 mar. 2013.

BAHIA. Constituição do Estado da Bahia, promulgada em 05 de outubro de 1989. Salvador: 2005. Disponível em: <www.mpba.mp.br/institucional/legislacao/constituicao_bahia.pdf >. Acesso em: 16 jun. 2013.

BARDIN, Laurence. Análise de conteúdo. Lisboa: Edições 70, 2006. [1. ed. 1977].

BONSÓN, Enrique et al. Local e-government 2.0: social media and corporate transparency in municipalities. Government Information Quarterly, Maryland, v. 29, n. 2, p. 123-132, abr. 2012.

BRASIL. Constituição da República Federativa do Brasil, de 05 de outubro de 1988. Brasília: Centro de Documentação e Informação - Edições Câmara, 37. ed. 2013. Disponível em: <bd.camara.gov. $\mathrm{br} / . . . /$ constituicao_federal_37ed_versao_reduzida.pdf $>$. Acesso em: 16 jun. 2013.

BRASIL. Lei $n^{\circ}$ 101, de 15 de dezembro de 2000. Lei de Responsabilidade Fiscal. Brasília: 2000. Disponível em: <www.planalto.gov.br/ccivil_03/leis/lcp/lcp101.htm> Acesso em: 16 jun. 2013.

BRASIL. Lei no 4.320, de 17 de março de 1964. São Paulo: Atlas, 1997.

BRASIL. Lei no 9.755, de 16 de novembro de 1998. Divulgação de Contas Públicas. Brasília: 1998. Disponível em: <www.contaspublicas.gov.br/LEI\%20N\%209755\%20.htm>. Acesso em: 16 jun. 2013.

BRESSER-PEREIRA, Luís C.; SPINK, Peter. Reforma do estado e administração pública gerencial. São Paulo: FGV, 2005.

CASTELLS, Manuel. A sociedade em rede: a era da informação. São Paulo: Paz e Amor, 2002.

CASTRO, Domingos P. Auditoria e controle interno na administração pública. São Paulo: Atlas, 2008.

COSTA, Luís Bernardo D. O Tribunal de Contas no Estado contemporâneo. Dissertação (mestrado em direito econômico e social) — Programa de Pós-graduação em Direito Econômico e Social, Pontifícia Universidade Católica do Paraná, Curitiba, 2005.

DIAMOND, Larry; MORLINO, Leonardo. Introdução. In: DIAMOND, Larry; MORLINO, Leonardo. Assessing the Quality of Democracy. Baltimore: The Johns Hopkins University Press, 2005. p. 9-13.

LAUDON, Jane P.; LAUDON, Kenneth C. Sistemas de informação gerenciais. 9. ed. Pearson: São Paulo, 2011.

LOH, Stanley. 31 tipos de sistemas de informação. Porto Alegre, 2014.

O'BRIEN, James A. Sistemas de informação e as decisões gerenciais na era da internet. 3. ed. Saraiva: São Paulo, 2011.

OCDE. The e-government imperative: main findings. Paris: Ocde, 2003.

PEREIRA, Jeronimo Rosário T. Gestão e controle de recursos públicos: um estudo sobre a rejeição de prestação de contas nos governos municipais do estado da Bahia. Dissertação (mestrado acadêmico 
em contabilidade) — Faculdade de Ciências Contábeis, Universidade Federal da Bahia, Salvador, 2010 .

PLATT NETO, Orion A. et al. Publicidade e transparência das contas públicas. Contab. Vista \& Rev., v. 18, n. 1, p. 75-94, jan./mar. 2007.

PRODESP Tecnologia da Informação. História: década de 1970. Disponível em: <www.prodesp. sp.gov.br/historia/historia.asp>. Acesso em: 29 dez. 2011.

RAUPP, F. M.; PINHO, J. A. G. Prestação de contas por meio de portais eletrônicos: um estudo em Câmaras Municipais da Grande Florianópolis. Revista Universo Contábil, v. 6, n. 3, p. 64-79 jul./ set. 2010.

RICHARDSON, Roberto J. et al. Pesquisa social: métodos e técnicas. São Paulo: Atlas, 1999.

ROCHA, Arlindo C. A realização da accountability em pareceres prévios do Tribunal de Contas de Santa Catarina. Rev. Adm. Pública, Rio de Janeiro, v. 47, n. 4, p. 901-925, jul./ago. 2013.

SAMPAIO FILHO, Carlos. Breve história do TCM-BA. 2000. Disponível em: <www.tcm.ba.gov.br $=>$ Institucional => História $>$. Acesso em: 16 jun. 2013.

SANCHEZ, Oscar A.; ARAÚJO, Marcelo. Avaliação dos mecanismos de controle da corrupção e de valorização da cidadania no estado de São Paulo. São Paulo: Cedec, 2006.

SILVA, Lino M. Contabilidade governamental: um enfoque administrativo. São Paulo: Atlas, 2008.

SIRAQUE, Vanderlei. Controle social da função administrativa do Estado: possibilidade e limites na Constituição de 2005. São Paulo: Saraiva, 2005.

YIN, Robert K. Estudo de caso: planejamento e métodos. Porto Alegre: Bookman, 2005.

ZAMOT, Fuad. Os tribunais de contas no governo eletrônico O SIGFIS do TCE-RJ: um estudo de caso. In: CONGRESO INTERNACIONAL DEL CLAD SOBRE LA REFORMA DEL ESTADO Y DE LA ADMINISTRACIÓN PÚBLICA, VIII, 2003, Panamá.

Audálio Fernandes dos Reis é mestre em administração pela Universidade Federal de Sergipe (UFS). E-mail: audalio@terra.com.br.

Antonio Luiz Rocha Dacorso é doutor em administração pela Faculdade de Economia, Administração e Contabilidade da Universidade de São Paulo (FEA/USP) e professor adjunto do Departamento de Administração da Universidade Federal de Sergipe (UFS). E-mail: antoniodacorso@gmail.com.

Fernando Antonio Guimarães Tenório é mestre em administração pela Universidade Federal de Sergipe (UFS). E-mail: fernandoagtenorio@gmail.com. 
